\title{
Impacto de la política proteccionista de Estados Unidos en la economía mexicana ${ }^{1}$ Impact of United States protectionist policy on the Mexican economy
}

Journal of Economic Literature (JEL):

F02, F13, F23, F36

Palabras clave:

Apertura comercial

Exportaciones, Importaciones

Aranceles, Proteccionismo

Incertidumbre

Keywords:

Trade Liberalization,

Exports, Imports,

Tariffs, Protectionism,

Uncertainty

Fecha de recepción:

28 de junio de 2016

Fecha de aceptación: 4 de agosto de 2017

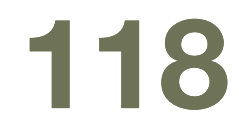

ECONOMÍAunam vol. 14, núm. 42, septiembre-diciembre, 2017

\section{Resumen}

Dados los resultados de bajo crecimiento económico, desempleo y déficit de comercio exterior en muchos países el artículo analiza el cuestionamiento a los acuerdos comerciales. El gobierno de Estados Unidos ha respondido con políticas proteccionistas. Deja a un lado los acuerdos comerciales multilaterales y opta por acuerdos bilaterales para tomar ventaja, frenar el crecimiento de importaciones y encarar sus problemas económicos. La economía mexicana saldrá seriamente afectada, dada su gran dependencia de la economía de Estados Unidos. El gobierno insiste en mantener los tratados comerciales sin considerar que hemos sido perdedores. El artículo se plantea la necesidad de cambio de estrategia de desarrollo; México se favorecería al salirse del TLCAN, pues tendría la posibilidad de tener una política económica para crecer hacia el mercado interno y sustituir a las importaciones.

\section{Abstract}

Given the results of low economic growth, unemployment and trade deficits in many countries, this paper analyzes the questioning of trade agreements. The us government has responded with protectionist policies, and it sets aside multilateral trade agreements and opts for bilateral agreements to take advantage, to curb the growth of imports and recrease their economic problems. The Mexican economy will be severely affected, given its heavy dependence on the us economy. The government insists on maintaining trade agreements without considering that we have been los-

1 Este trabajo se inscribe en el Proyecto PAPIIT IN304215, titulado Estancamiento y Desigualdad: Procesos que se Retroalimentan (1990-2014) auspiciado por la Dirección General de Apoyo al Personal Académico de la UNAM.

(C) 2017 Universidad Nacional Autónoma de México, Facultad de Economía. Este es un artículo Open Access bajo la licencia CC BY-NC-ND (http://creativecommons.org/licenses/by-nc-nd/4.0/). 
ers. The paper there is a need to change development strategy; Mexico is favored if it leaves NAFTA, since it would have the possibility of having an economic policy to grow towards the domestic market and substitute imports.

\section{Los resultados y el cuestionamiento de la apertura comercial}

Los países al decidir abrir sus economías y dejar a un lado los permisos previos de im-

portación -los cuales prohibían la importación de aquellos productos que pasaban a ser producidos internamente-, pasaron a establecer aranceles, tarifas y cuotas de importación para así regular las importaciones.

En 1994 entró en funciones el Tratado de Libre Comercio de América del Norte (TLCAN), firmado por Estados Unidos, Canadá y México. Por lo general en los acuerdos comerciales se impone la voluntad del país más fuerte a favor de sus empresas y no se busca el beneficio del país vecino. En las negociaciones, el país hegemónico (Estados Unidos), da a cambio concesiones a los otros países que no afecten su dinámica económica, sino que son complementarias a sus intereses.

Los países tratan de contrarrestar las deficiencias productivas y competitivas mediante los acuerdos comerciales, al establecer aranceles a las importa-

En México los márgenes de libertad para determinar su política económica se han visto reducidos debido a Ios acuerdos comerciales; dejó de tener una política industrial, agrícola y crediticia a favor de los nacionales, y se compromete a dar trato similar

a la inversión extranjera ciones, para que éstas no pasen a ser mayores que las exportaciones o desplacen a la producción nacional. Se negocian niveles de aranceles y se prohíben las políticas no arancelarias de restricción de importaciones. Así, en los tratados de libre comercio (TLC) se han reducido drásticamente y hasta han desaparecido los aranceles y tarifas.

Se han establecido porcentajes de valor agregado en las exportaciones entre los países miembros. México puso a disposición del TLCAN las compras gubernamentales y abrió la inversión de los países miembros en varios sectores estratégicos de su economía. Ello propicia que el país hegemónico, imponga el respeto y pago a las patentes, derechos de autor y de tecnología. Los países desarrollados protegen su tecnología, pero no se socializa, por lo cual prosiguen y se profundizan las diferencias de productividad y competitividad, así como del ingreso entre países. Como señala Dean Baker (2016) "la redistribución ascendente no puede atribuirse simplemente a la 'tecnología', sino que fue el resultado de decisiones de política que estaban destinadas a este propósito".

En México los márgenes de libertad para determinar su política económica se han visto reducidos debido a los acuerdos comerciales; dejó de tener una política industrial, agrícola y crediticia a favor de los nacionales, y se compromete a dar trato similar a la inversión extranjera, siendo que ésta cuenta con mejores condiciones financieras, tecnológicas y estrategias de mercado que las nacionales. Los inversionistas extranjeros pasan a exigir aseguramiento de la rentabilidad y de su capital. El gobierno no puede tener injerencia en la economía más allá de lo establecido en dichos acuerdos comerciales, no se puede incrementar salarios ante el temor de pérdida de competitividad, ni siquiera puede sancionar a las empresas por atentar contra el medio ambiente, ni establecer políticas impositivas para mejorar el financiamiento 
del gobierno. Los tratados de libre comercio y la Organización Mundial de Comercio (OMC), no permiten la instrumentación de subsidios a las exportaciones, pero a pesar de ello, Estados Unidos y otros países los instrumentan, lo que genera que el más fuerte establezca políticas a su favor, independientemente de los acuerdos bilaterales o multilaterales acordados. Estados Unidos trata de imponer a nivel mundial el no manejo de la política cambiaria como instrumento competitivo, lo cual atenta también sobre el manejo soberano de la política económica de los otros 'socios comerciales' que la establecen para proteger y estimular su crecimiento.

Algunos acuerdos comerciales contemplan que en el caso de disputas comerciales entre países, se tiene que ir a tribunales privados internacionales, lo cual atenta sobre la soberanía de los países para decidir sobre sus políticas económicas. Así, un país no puede anteponer su preocupación por el medio ambiente, sobre las ganancias de las empresas transnacionales que pasan a operar en su país, Dean Baker nos dice que "estos tribunales pueden ser utilizados para penalizar a los gobiernos por medidas diseñadas para proteger el medio ambiente, a los consumidores, a los trabajadores o para asegurar la estabilidad de las instituciones financieras" (2017). En las renegociaciones del TLCAN, Estados Unidos busca que sea en sus tribunales donde se diriman las controversias, los cuales actuarían a favor de ellos y en detrimento de México y Canadá.

\section{2. ¿México ha sido exitoso en el TLCAN?}

México ha perdido en el TLCAN y en el resto de los Tratados de Libre Comercio, sin embargo, es visto por Donald Trump y por muchos economistas como un país exitoso, por su crecimiento de exportaciones y su superávit de comercio exterior con respecto a Estados Unidos. Sin embargo, dichos resultados dejan de lado muchos aspectos importantes, tales como el alto componente importado de las exportaciones manufactureras y el gran crecimiento de importaciones derivado de la apertura comercial, que nos lleva a importar más de lo que vendemos al exterior. México tiene superávit de comercio exterior con Estados Unidos, pero tiene déficit comercial con China, con el resto de Asia y con la Unión Europea (véase Tabla 1), dando por resultado un déficit comercial, así como desindustrialización, bajo crecimiento económico y creciente dependencia de la entrada de capitales.

\begin{tabular}{|l|c|}
\hline \multicolumn{2}{|l|}{ Tabla 1. Balanza Comercial } \\
\hline \multicolumn{1}{|c|}{ X-M } & 2015 \\
\hline Estados Unidos & $+122 \mathrm{mmd}$ \\
\hline Unión Europea & $-25 \mathrm{mmd}$ \\
\hline China & $-65 \mathrm{mmd}$ \\
\hline Resto de Asia & $-54 \mathrm{mmd}$ \\
\hline
\end{tabular}

Fuente: INEGI.

Detrás del déficit de comercio exterior que existe en nuestro país, están los diferenciales de productividad y competitividad que tenemos con nuestros principales socios comerciales, como los rezagos productivos. Si tales acuerdos comerciales y 
la mayor apertura económica que generan (la apertura económica pasó de ser 29.3\% en 1994 a $65.85 \%$ en 2014, véase Tabla 2), resultan en crecientes déficit de comercio exterior para algún país, es que los aranceles establecidos o la eliminación de los mismos, no contrarrestaron los diferenciales de productividad y competitividad que los llevaron a ser perdedores. Si Donald Trump dice que Estados Unidos es perdedor frente a México, no es porque nuestro país haya negociado mejor que ellos o que haya impuesto políticas favorables al país. Quienes han ganado han sido las empresas transnacionales establecidas en México, que son sobre todo de Estados Unidos, han aprovechado el tratado comercial para importar insumos baratos de China y el resto de Asia para reducir costos, utilizan la mano de obra barata en México y las ventajas de su localización, para de aquí exportar a Estados Unidos. Ello explica porqué México muestra un gran superávit de comercio exterior con Estados Unidos, y en cambio tiene un creciente déficit de comercio exterior con China y el resto de Asia.

\begin{tabular}{l|c|c|}
\hline Tabla 2 \\
\hline \multicolumn{1}{|c|}{ Apertura Económica } & 1994 & 2014 \\
\hline X + M/PIB & $29.30 \%$ & $65.85 \%$ \\
Fuente: INEGI. & & \\
\hline
\end{tabular}

La apertura comercial, así como los bajos aranceles y la apreciación del tipo de cambio -que en México permaneció igual desde los principios de la década de 1990 hasta 2014-, han llevado a que las importaciones crezcan más que las exportaciones y a incrementar el déficit de comercio exterior, lo cual ha roto cadenas productivas y se ha reducido la participación de la producción manufacturera en el PIB (véase Tabla 3).

\begin{tabular}{|c|c|}
\hline 1990-1999 & $19.2 \%$ \\
\hline 2014 & $16.7 \%$ \\
\hline
\end{tabular}

En la Figura 1, podemos observar el comportamiento del déficit de comercio exterior de la industria manufacturera que incluye maquila, la cual, al ser superavitaria reduce el déficit total de dicha industria; al caer las exportaciones de maquila con las políticas proteccionistas de Estados Unidos, el déficit manufacturero total si se incrementará significativamente y no podrá financiarse. De aplicarse políticas contraccionistas y devaluatorias para ajustar dicho déficit, tendrá un fuerte costo económico, político y social, lo cual obligará al gobierno a recurrir a las políticas proteccionistas.

La apertura comercial generalizada está siendo cuestionada debido a que no todos los países resultan beneficiados con ello; hay ganadores y perdedores, en función de los niveles de productividad y competitividad de sus productos. 


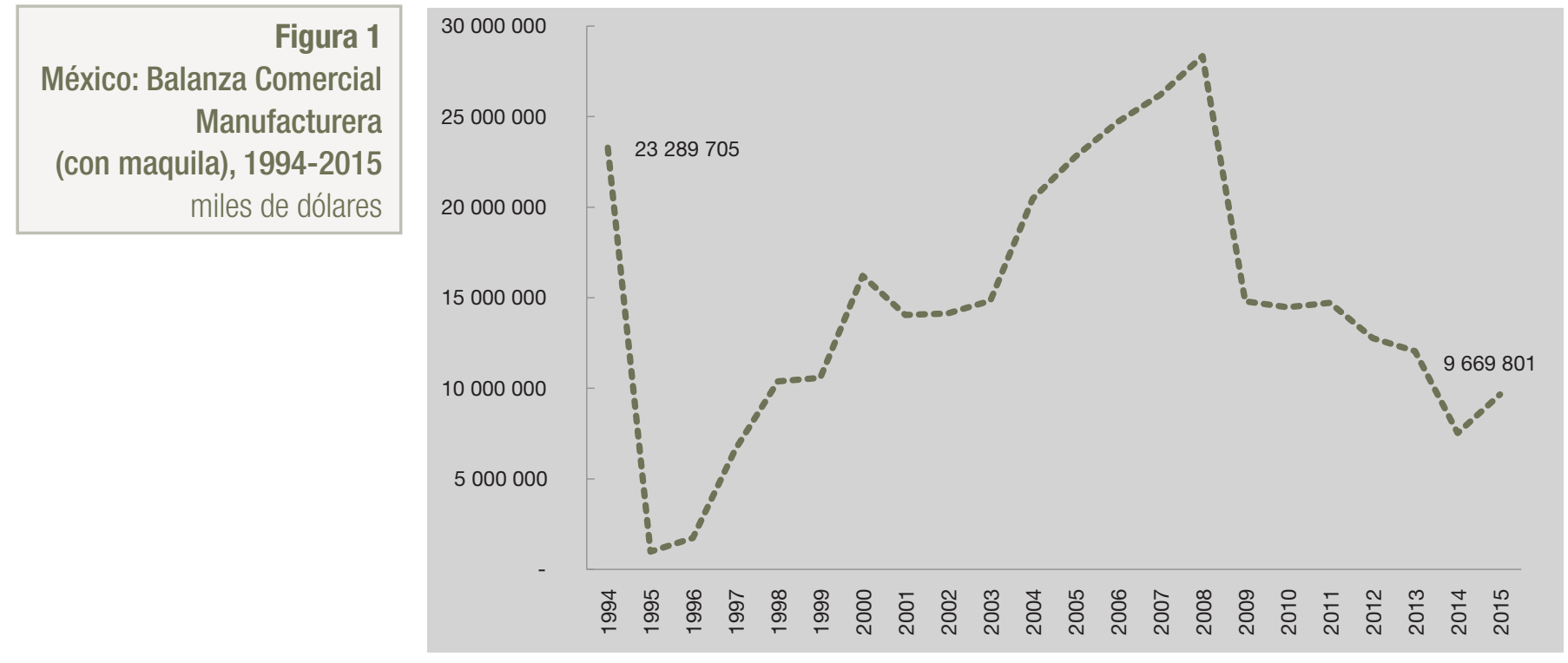

Fuente: BIE INEGI, 2017.

\section{El porqué de las políticas económicas de Donald Trump}

La política económica que ha implementado Donald Trump, recoge demandas de empleo bien remunerado, él adjudica dichos problemas a los tratados comerciales que Estados Unidos ha firmado, que según él han sido mal negociados y han llevado al déficit de comercio exterior, a la desindustrialización, al bajo crecimiento y la menor generación de empleo. De ahí la política proteccionista, como la flexibilidad de la política fiscal y la desregulación financiera, esperando que dicha política genere mayores opciones de rentabilidad y de financiamiento, para impulsar la inversión que requiere el crecimiento y la mayor generación de empleo en el sector manufacturero. Pretende reducir el déficit de comercio exterior a través de políticas proteccionistas, ya que éste representa menos creación de empleos para su país. Así, el déficit de comercio exterior de Estados Unidos en 2015 fue de 500 mil millones de dólares.

La flexibilización de la política fiscal estadounidense y la política proteccionista, tiene como objetivo abrir oportunidades de inversión rentables a muchas empresas, para crecer en torno al mercado interno. Muchos señalan que la flexibilización fiscal llevará a déficit fiscal, mayor deuda, presiones inflacionarias y aumento de la tasa de interés. Sin embargo, no tiene problemas financieros, aunque se endeuda, tiene control de su moneda, puede refinanciarse permanentemente y el resto del mundo adquiere deuda de dicho país. Además, tienen baja tasa de interés y está por debajo del crecimiento económico actual, por lo que puede estar protegido de las obligaciones financieras que deriven de la mayor deuda, sin que se incremente su monto. Al incrementar la inversión, originará efectos positivos sobre la productividad, lo que evitará presiones sobre los precios.

La política de restricción a importaciones favorece la producción nacional y promueve la sustitución de importaciones, la reducción del déficit de comercio exterior y el crecimiento económico. Se ha dicho también que originará inflación, por el freno a 
las importaciones; hay que tomar en cuenta que esta política va acompañada de una reducción de impuestos a las empresas y que predomina un dólar apreciado, dada la devaluación del resto de las monedas, lo que le permite a Estados Unidos comprar barato, y así no enfrentará presiones sobre los precios. La política proteccionista del presidente Trump, surge en un contexto donde el comercio internacional ha dejado de crecer, como resultado de la desaceleración del crecimiento de la economía mundial; de ahí su intensión de crecer hacia adentro.

\section{Multilaterialismo, individualismo y bilaterialismo}

El presidente estadounidense Trump, se ha pronunciado contra los acuerdos regionales, como el Acuerdo Transpa-

cífico de Cooperación Económica (TTP en sus siglas en inglés), ha dicho que está por el libre comercio y que procederá a negociar acuerdos comerciales bilaterales, que sean benéficos para su país. Evidenciando que en tales negociaciones impondrá el poder y fuerza de su gobierno frente a cada país con que establezca dichos acuerdos, por lo que es de prever, que el resto de los países saldrán afectados. No dejarán atrás la apertura comercial y las inter-conecciones comerciales que se han desarrollado con la globalización. Para no recibir una respuesta generalizada de freno a sus exportaciones, es que plantean acuerdos bilaterales para negociar y establecer acuerdos favorables para aquellos productos que consideren que son importantes para impulsar la producción en su país, con el propósito de generar efectos multiplicadores internos a favor del empleo, reducir su déficit de comercio exterior y volver a ser la gran potencia.

En el caso de México, se va a revisar el TLCAN, donde Estados Unidos no buscará como beneficiar a México, dado que Trump considera que México se ha aprovechado de Estados Unidos, por lo que pretende imponer más cosas a favor de Estados Unidos y México no tiene capacidad de negociación alguna. Estados Unidos buscará frenar las importaciones manufactureras provenientes de México, así como incrementar más sus exportaciones hacia nuestro país. Sin embargo, su mayor problema será con China, dada su fuerza económica, que es a su vez es el principal acreedor de Estados Unidos y que, además, representa un mercado significativo para las exportaciones estadounidenses. Por lo que lo más probable es que lleguen a celebrar acuerdos comerciales y que se dividan las ramas industriales en las negociaciones que tengan. Por ejemplo, los bienes de capital los peleará Estados Unidos, a cambio de dejarle a China la industria de juguetes y otras de menor importancia.

\section{Predominio del individualismo}

Junto con la apertura comercial y financiera dejaron de existir las políticas de cooperación económica; y se dio lugar al predominio la búsqueda del beneficio en favor de las empresas transnacionales y del capital financiero, que hegemoniza el proceso de globalización; se dejaron atrás las políticas de cooperación que algunos países desarrollados instrumentaron durante la posguerra en beneficio de los más necesitados. No hay país que busque reducir las diferencias de crecimiento y desarrollo entre los países, sino que todos buscan crecer a costa de los otros, tampoco 
Ante los problemas

de bajo crecimiento, desempleo, bajos salarios

y reclamos crecientes

de la población, algunos

países han privilegiado

las políticas encaminadas

a beneficiar los intereses

nacionales y dejar de

lado la cooperación

internacional

hay política de cooperación y solidaridad internacional para reducir las diferencias entre países ricos y exitosos, en relación a los demás, que han visto deteriorada su esfera productiva, que enfrentan altos niveles de endeudamiento, bajo o nulo crecimiento, alto desempleo y deterioro del nivel de vida de su población. Ello ha llevado a que los países que caen en crisis, no reciban trato preferencial ni apoyos financieros incondicionales para que retomen el crecimiento, sino por el contrario, los "apoyos" que reciben de las instituciones financieras internacionales vienen condicionados a la instrumentación de políticas de ajuste, que se encaminan a asegurar el reembolso de sus deudas, a costa de acentuar los problemas de crecimiento, desempleo y deterioro de las condiciones de vida de la población, lo que exacerba las distancias entre los países acreedores y los deudores, al pasar a estar más controlados y subordinados.

Ante los problemas de bajo crecimiento, desempleo, bajos salarios y reclamos crecientes de la población, algunos países han privilegiado las políticas encaminadas a beneficiar los intereses nacionales y dejar de lado la cooperación internacional. Los países optan por retomar el manejo soberano de su política económica para encarar sus problemas, dejan de participar en uniones económicas, como el caso del Brexit o de acuerdos multilaterales comerciales, como es el caso de Estados Unidos, debido a que tales políticas no generaron los objetivos esperados de crecimiento y bienestar.

Los gobiernos tienen que responder a las demandas de sus votantes, por lo que pasan a relegar los objetivos de solidaridad internacional y obligan al resto a volcarse hacia lo interno, considerando que lo internacional ya no seguirá actuando a su favor.

\section{El cuestionamiento de EU a los acuerdos multilaterales de apertura comercial}

Geoff Pigman (2016) señala que "una retirada estadounidense del comercio mundial acelerará el crecimiento de China en relación con Estados Unidos".

De darse ello, sólo acontecería en el corto plazo, dado que el resto de los países verá incrementado rápidamente su déficit de comercio exterior con China, el cual no podrán financiar, dado que, en principio, verán reducido el superávit comercial que tienen con Estados Unidos, al instrumentar éste políticas proteccionistas, por lo que no podrán mantener su apertura comercial, y terminarían por frenar de nuevo el crecimiento de las exportaciones de China.

Lo más probable es que las restricciones no sean para todas las importaciones, ya que de concretarse el crecimiento económico de Estados Unidos, tanto por la flexibilización de la política fiscal, como por el regreso de inversiones para sustituir las importaciones, requerirán de materias primas que tendrán que ser importadas, dado que la sustitución de importaciones no será generalizada, sino que se centrarán en aquellas industrias más dinámicas con efectos multiplicadores a favor de la producción y el empleo de su país, por lo que se beneficiarán aquellos países que les abastezcan de las materias primas necesarias para su desarrollo. 
7. Impacto de la política comercial bilateral de Estados Unidos sobre el resto de las economías
La política que Estados Unidos vaya a instrumentar respecto de disminuir la entrada de importaciones a su mercado, viene a replantear el contexto

de apertura comercial predominante e implicará una caída en las exportaciones de varios países hacia dicho mercado.

De los acuerdos comerciales bilaterales que Estados Unidos impulse, habrá países que no aceptarán los términos impuestos por ellos y cada país tratará de defender su industria y no perder posiciones comerciales. Si mantienen el acuerdo comercial con Estados Unidos y este establece restricciones a los productos que le interesa recuperar para producir, sus socios comerciales responderán también con barreras a las importaciones que les interesa producir en su país y que son esenciales para crecer hacia el mercado interno.

Tal política comercial afecta a las empresas transnacionales que realizan procesos productivos (cadenas de valor) en varios países, que aprovechan las ventajas comparativas, competitivas y de localización que ofrecen. Tales empresas ejercerían su poder económico y político para oponerse a medidas que afecten sus intereses. De establecerse aranceles a las importaciones en Estados Unidos, obligará a las empresas a acotar las cadenas de valor (Krugman, 2016), así como trasladarse hacia los países que no sean sujetos de dichos aranceles, dado el impacto que éstos tendrán sobre los precios de los productos y sobre las ganancias de dichas empresas. Los gobiernos tienen que ofrecer condiciones de rentabilidad y de mercado

La política proteccionista

de Estados Unidos tiende a

agravar los problemas del sector externo y el crecimiento

de México para estimular la inversión, así como para impulsar la sustitución de importaciones. En las renegociaciones la preocupación que estará presente es favorecer a las industrias y cadenas productivas que podrán impulsar en su país y el efecto multiplicador interno de ello sobre el crecimiento, en la generación de empleo y en la balanza de comercio exterior.

La política proteccionista de Estados Unidos tiende a agravar los problemas del sector externo y el crecimiento de México, dado el alto porcentaje de exportaciones que se destinan a dicho país, lo que coloca al país en una situación de fragilidad y de incapacidad de pago de su deuda -que le aumentará el riesgo al país-, con la consecuente restricción crediticia internacional y el aumento de la tasa de interés, y complicará más aún tal situación. En nuestro caso, se afectarán las industrias que venían creciendo hacia fuera y también se verá afectado el sector de comercio y servicios, ligado a las exportaciones e importaciones.

Al no tener una posición de fuerza sólida frente al gobierno de Estados Unidos, México sufrirá recortes a los productos de alta manufactura, por lo que perderemos más industria y más empleo, y su comercio exterior será reducido a exportaciones de materias primas y agroindustriales, que no contrarrestan el desempleo y la pérdida de crecimiento que se deriva de la caída de las exportaciones manufactureras, por lo que se aumentarán las presiones sobre el déficit de comercio exterior y se frenará el crecimiento económico. Tal situación hará insostenible la apertura comercial y tendrán que instrumentar políticas proteccionistas ante el hecho de que muchos no 
tendrán condiciones para financiar déficit de comercio exterior crecientes, ni podrán realizar permanentemente ajustes restrictivos y devaluatorios para reducir el déficit del sector externo, dado el alto costo económico, político y social que implicaría la contracción económica y las presiones inflacionarias.

Si no llegan a celebrar acuerdos comerciales, habrá ruptura y se sujetarán a las normas y aranceles establecidos en la Organización Mundial de Comercio, con la que estarán mejor que con los aranceles que quiere establecer Estados Unidos.

El hecho de que México tenga acuerdos comerciales con 44 países, ya no es atractivo para los inversionistas extranjeros, pues el principal mercado es el de Estados Unidos y éste establecerá altos aranceles a las importaciones provenientes de México. A pesar de que el gobierno mexicano, ha señalado que buscará diversificar sus exportaciones, el problema es que el mercado internacional se está desacelerando, y no tiene nada que hacer frente a China, por lo que terminará instrumentando políticas proteccionistas para proteger su mercado y reducir el déficit de comercio exterior.

\section{El problema comercial de Estados Unidos no es con México, sino con China}

El mayor problema económico de Estados Unidos no es frente a

México, donde ellos tienen un déficit comercial de bienes (en sus estadísticas) por 60 mil millones de dólares ( $\mathrm{mmd}$ ), sino frente a China, que es por 368 mmd en 2015 y con ellos no tiene ningún tratado que favorezca el libre comercio. China exporta a Estados Unidos $484 \mathrm{mmd}$ y Estados Unidos le exporta a China productos por 116 mmd. Las negociaciones comerciales con China serán diferentes, dado que dicho país es el gran acreedor de Estados Unidos. Si el presidente Trump se pone agresivo frente a China, éste país puede vender los bonos de Estados Unidos y originarle fuertes problemas financieros y ello podría afectar a México, dado que no tenemos poder de negociación frente a los estadounidenses.

Donald Trump ha empezado su gobierno con una fuerte ofensiva contra México, señalando que disminuirá el déficit de comercio exterior que tienen con nuestro país. Datos de la Oficina Ejecutiva del Presidente de Estados los Unidos señalan que, en 2015 México fue el $2^{\circ}$ mercado más grande de exportaciones de bienes de dicho país por $236 \mathrm{mmd}$, lo que representa $15.7 \%$ del total de sus exportaciones. Por otro lado, México es el $3^{\text {er }}$ oferente más grande de productos importados de Estados Unidos, por 295 mmd, Estados Unidos importa vehículos de México por 74 mmd, maquinaria eléctrica por $63 \mathrm{mmd}$, instrumentos médicos y ópticos por $12 \mathrm{mmd}$, que es lo que más les interesaría impulsar en su país, pues ocupa mano de obra calificada y ello representa $50.5 \%$ de sus importaciones provenientes de México. Cabe señalar que $40 \%$ de dichas importaciones tienen valor agregado, que proviene de su país, por lo que al reducir dichas importaciones, afecta las exportaciones que ellos realizan a México. Con la revisión del TLCAN, quieren aumentar el valor agregado de los productos provenientes de los países miembros, a fin de reducir el componente importado que proviene de China y del resto de los países asiáticos. Las empresas que exportan manufactura de México a Estados Unidos triangulan; importan insumos de China 
y del resto de Asia, aprovechan la mano de obra barata de México para exportar a Estados Unidos.

En la Tabla 4, podemos ver como se han reducido significativamente las importaciones que México realiza de Estados Unidos a partir del año 2000, se ha incrementado la presencia de productos provenientes de China y del resto de los países de Asia, lo cual explica en gran medida el ingreso de China a la OMC en el 2001, pues le ha permitido penetrar a todos los mercados a nivel mundial y tener superávit comercial con la mayoría de ellos.

\begin{tabular}{|l|c|c|}
\hline \multicolumn{2}{|c|}{ Tabla 4. Origen de las Importaciones de México (en \%) } \\
\hline
\end{tabular}

Fuente: INEGI.

Lo que Estados Unidos desea en las negociaciones comerciales con México, es aumentar el valor agregado de las exportaciones de México hacia Estados Unidos y Canadá con productos de la región, a fin de reducir los componentes importados provenientes de China y del resto de Asia. Por ejemplo, los materiales de un auto, $62.5 \%$ debe ser de los países del TLCAN y quiere aumentar dicho porcentaje a fin de reducir el proveniente de otros países. Estados Unidos tratará que ese mayor valor agregado, sea de productos provenientes de su país, para impulsar la producción y el empleo. Hay quienes señalan que eso sería más benéfico que un impuesto alto a las importaciones de autos que ellos puedan establecer, pero de establecerse, representa para México un reto para impulsar la producción nacional, respecto a ese mayor valor agregado que incorpore cada país, sin embargo, no se tiene política industrial que lo haga posible.

La política arancelaria de Estados Unidos implicará una fuerte caída de las exportaciones de nuestro país a dicho mercado, el cual representa $82.69 \%$ de nuestras exportaciones en 2016. De establecerse altos aranceles a las importaciones, la industria automotriz, así como de aquellos productos que antes se producían en Estados Unidos, se afectarían las exportaciones, que sobre todo de las empresas estadounidenses ubicadas en México. Esto lo hacen con el fin de que tales empresas regresen a su país, para impulsar la generación de empleo y crecimiento y tratarían de compensar los mayores costos de las importaciones con la reducción de impuestos a las empresas, la desgravación del ingreso de las exportaciones, como con la apreciación del dólar, para asegurar condiciones de rentabilidad para impulsar la inversión y producción de tales productos en su país (Farhi, et al., 2017).

Para el caso de la producción pesada que pretenden impulsar en su país, requerirán un gran crecimiento de la productividad para abaratar costos y evitar tener presiones sobre los precios; como resultado del freno a importaciones, del mayor costo de su mano de obra y el hecho de que los salarios tenderán a aumentar, por el mayor crecimiento económico que impulsen y la mayor generación de empleo. El 
problema es que la sustitución de importaciones lleva tiempo y se requiere de altos niveles de productividad, a fin de garantizar el abasto interno a bajo costo, por lo que en un corto período se presentarían presiones sobre los precios.

Donde no podrán avanzar -en la sustitución de importaciones-, es en la producción de bienes agrícolas, dados los diferentes climas, lo que representará presiones sobre los precios de bienes de consumo salarial, que impactará sobre los salarios, mermando más su competitividad en el mercado internacional. Hay que tomar en cuenta, que las importaciones agrícolas que realiza Estados Unidos provenientes de México son por $21 \mathrm{mmd}$ y cabe destacar que somos el segundo oferente más grande de productos agrícolas a dicho país. México abastece un tercio de las frutas que importa Estados Unidos, y 2/3 partes de los vegetales.

Todo apunta a que Estados Unidos quiere quedarse con la producción manufacturera y dejar que México le exporte sólo insumos productivos y productos agrícolas, lo que nos condenaría a más subdesarrollo del que ya tenemos. La posición del gobierno de México de renegociar el TLCAN en una perspectiva en donde todos ganen, no es posible.

Si bien es atribución del Presidente de Estados Unidos la instrumentación de políticas arancelarias, la modificación del TLCAN tiene que pasar por el Congreso de ambos países. Se dijo a inicios de febrero de 2017 que el Congreso de Estados Unidos tiene 90 días para revisar los acuerdos comerciales antes de su firma.

\section{9. ¿Cuál será el impacto de las políticas proteccionistas de Estados Unidos en la economía mundial?}

Algunos economistas, señalan que las políticas proteccionistas llevarán a la economía mundial a la recesión. Tal posición, no toma en cuenta que las políticas proteccionistas durante la Posguerra generaron condiciones de crecimiento, tanto en países desarrollados, como en desarrollo. El control de movimientos de capitales y mercancías, dio márgenes de maniobra para flexibilizar la política

La economía de Estados Unidos tendrá posibilidades de crecer con la flexibilidad

de la política fiscal y

la política de alza de

aranceles, pero ello no significará un impulso a la

economía mundial monetaria, fiscal y crediticia a favor del crecimiento. La mayoría de las economías se desaceleraron cuando dejaron dichas políticas y optaron por la apertura comercial en la década de 1980.

La economía de Estados Unidos tendrá posibilidades de crecer con la flexibilidad de la política fiscal y la política de alza de aranceles, pero ello no significará un impulso a la economía mundial, dado que procurarán evitar filtraciones de demanda hacia importaciones de bienes manufacturados -como ya se señaló-, a través de limitar su ingreso.

En relación al hecho que el crecimiento que se impulsará en Estados Unidos, a partir de la flexibilidad fiscal y de la política proteccionista, demandará mano de obra, ejercerá presión sobre los salarios, y ello se acentuaría por el freno a la inmigración y la expulsión de ilegales, que ha empezado a instrumentar el gobierno de Donald Trump. Es decir, se disminuirá la oferta laboral, para presionar sobre mejores salarios, ante la mayor demanda de empleo, y se generará el crecimiento económico esperado. Las inversiones pueden frenarse por la falta de mano de obra, que es probable ello acontezca en ciertas ramas económicas, como en la construcción, 
el sector agrícola y en ciertos servicios donde operan los inmigrantes; por lo que los sectores empresariales afectados generarán presión, lo que puede llevar al gobierno a limitar su política contra los inmigrantes.

Surge la pregunta de si las medidas que Estados Unidos establece, reestablecerán el empleo perdido, al considerar el gran avance tecnológico que se ha dado en robotización, automatización en muchas ramas industriales. Nos dice Ed Dolan que al darse el regreso de empresas, favorecería sobre todo a trabajadores altamente calificados, no a los de baja calificación que fueron los que apoyaron a Trump (2016). La tendencia es que cada vez se generen menos empleos en la industria manufacturera, dado que seguirá la automatización y la robotización. El propósito de la política proteccionista y de la de estímulos fiscales, de recuperar industrias que se han ido a otros países y así impulsar efectos multiplicadores internos para generar empleo y mejores salarios, no será suficiente para alcanzar los objetivos de empleo y bienestar prometidos en campaña. Hasta ahora, no ha presentado una política de empleo, que ofrezca empleo bien remunerado a aquellos que son desplazados del sector manufacturero por la automatización.

\section{La incertidumbre de la economía y sus consecuencias}

Ante las consecuencias que se derivan de la instrumentación de la

política proteccionista por parte de Estados Unidos sobre el comercio internacional, propicia que las decisiones de inversión -tanto de Estados Unidos, como de sus principales socios comerciales-, se posterguen hasta ver cómo queda la renegociación de los acuerdos comerciales y la recomposición del aparato productivo.

La incertidumbre y la falta de expectativas de crecimiento, lleva a las empresas que cuentan con efectivo -recursos-, a optar por la inversión financiera, sea en bonos seguros o especulando en el mercado de capitales, lo que ha llevado al crecimiento de éstos.

Aún no hay conocimiento preciso de las dimensiones de las políticas económicas que vaya a instrumentar el gobierno en Estados Unidos, y de cómo impactará ello en el crecimiento de las exportaciones y en el flujo de divisas hacia México; por lo tanto, sobre las variables macroeconómicas y la dinámica nacional, se crea un clima de incertidumbre, que presiona sobre el riesgo de inversión, en torno a si éstas asegurarán o no el flujo de ingresos que permita su recuperación. Ello, aunado a la respuesta gubernamental de contracción del gasto público y el alza de la tasa de interés, se configura un panorama de desaceleración de la actividad económica, que frena aún más el crecimiento de la inversión privada nacional y extranjera, lo que acentúa más las perspectivas de menor crecimiento económico en el país, como las presiones sobre el tipo de cambio. Nos dice Michael Spence, que un factor del estancamiento es la incertidumbre en torno a la economía, y el impacto de las políticas sobre las diferentes variables (2016). Y justo lo que vemos, es que las políticas de ajuste instrumentadas atentan más contra el crecimiento, el empleo y la distribución del ingreso.

La devaluación del peso, las presiones sobre las finanzas públicas y el sector externo, derivadas de los bajos precios internacionales del petróleo, la caída de ex- 
portaciones y de la entrada de capitales -aunado a las políticas de ajuste restrictivas-, genera un entorno de incertidumbre sobre la economía del país, que frena las decisiones de inversión y propicia la salida de capitales, para protegerse de mayores devaluaciones y desestimula su entrada.

Cuando la economía deja de ser atractiva al capital, se incrementa la incertidumbre en torno al cumplimiento de las obligaciones que se tiene con el exterior. No sólo pasa a comprometerse el financiamiento del déficit externo, sino el propio contexto de apertura económica.

Ante la menor entrada de capitales, no puede mantenerse el déficit de cuenta corriente, lo que obliga a ajustarlo, sea a través de dejar flotar el tipo de cambio, como con políticas restrictivas para contraer la actividad y las importaciones o impulsando la sustitución de importaciones o replantear y renegociar el pago del servicio de la deuda externa e instrumentar políticas proteccionistas.

No hay condiciones internas ni externas, que actúen favorablemente para ajustar el déficit de comercio exterior, tampoco se ha incrementado la producción para sustituir las importaciones e incrementar las exportaciones, ni hay crecimiento de demanda externa para ello. Y mientras ello continúe, la economía seguirá en tendencia decreciente, tendrá que recurrir a hacer uso del crédito puente que le otorgó el Fondo Monetario Internacional (FMI) por 78 mil millones de dólares para atender las demandas por dólares, como para financiar el déficit de cuenta corriente, aumentará el riesgo del país, lo que dificultará obtener mayores créditos, además de que aumentará la tasa de interés, complicándose más la problemática del país.

Se intentó la estrategia de crecimiento con una economía abierta y crecimiento hacia fuera y no resultó, pues generó crisis y desaceleración económica e incertidumbre.

\section{Incertidumbre por las políticas proteccionistas de Estados Unidos}

Al parecer en el gobierno mexicano hay voluntad política para encarar los retos que sobre la economía nacional, originará la política que está instrumentando Donald Trump, que se manifiesta en la expulsión de connacionales, la caída de exportaciones, así como en la menor entrada de divisas y capitales al país. No muestra imaginación, creatividad, capacidad, ni voluntad para encarar tal situación; tampoco preocupación alguna por instrumentar políticas que impulsen el crecimiento económico, la generación de empleo, para que reduzca las presiones sobre el sector externo.

El presidente de México Enrique Peña Nieto, en un discurso pronunciado frente a las empresas exportadoras en León Guanajuato el 2 de diciembre de 2017, señaló que, México le sigue apostando por

el libre comercio y mira hacia los cuatro puntos cardinales, por lo que está impulsando una estrategia de expansión y diversificación comercial que consiste en la expansión hacia nuevos mercados y profundizar los ya existentes y que se aprovechará la base de negociación del TPP para alcanzar tratados bilaterales". Reiteró que "tenemos claros 
los temas e intereses para México. Buscaremos espacios para mejorar y modernizar el TLCAN, bajo la premisa de ganar-ganar.

El gobierno mexicano en sus 10 puntos de negociación frente a Estados Unidos, presentados el 23 de enero de 2017, insiste en preservar el libre comercio con Estados Unidos y Canadá, e incluye a los sectores de telecomunicaciones, energía y comercio electrónico en las negociaciones. Abre todo al capital internacional, deja de haber sectores estratégicos bajo el control del gobierno. Aunque con la reforma energética ya se había abierto el sector energético, frente a la posición del diferencial de salarios entre México y Estados Unidos, el presidente Peña Nieto dijo que se mejorarán los salarios conforme a la productividad, pero no hace nada para que ello ocurra, sino al contrario, está disminuyendo la inversión, por lo que hay menos condiciones para aumentar la productividad y los salarios. El Secretario de Economía declaró el $1^{\circ}$ de febrero de 2017, que dejar el TLCAN sería contrario al interés nacional. Aseguró que las empresas y la sociedad en general se han beneficiado del TLCAN. Como ejemplo está el record de las exportaciones agroalimentarias en 2016 por 27 mmd. La Secretaría de Hacienda y Crédito Público, insiste en las políticas macroeconómicas de 'estabilidad' y su búsqueda de los equilibrios macroeconómicos.

El gobierno mexicano mantiene la postura de seguir apostando a

La incertidumbre no se

combate con políticas

contraccionistas, pues éstas

no ofrecen expectativas de

crecimiento para promover

la inversión, ni resuelven las

presiones sobre el sector

externo y las finanzas

públicas la apertura comercial, sin reconocer que ello nos ha llevado a tener menos industria, menos empleos productivos, mayor endeudamiento tanto interno como externo y a depender de la entrada de capitales, a estar en la gran fragilidad y vulnerabilidad en que nos encontramos; donde las variables externas han pasado a actuar en forma negativa y no tenemos condiciones productivas, ni manejo de política económica para hacer frente a tal situación. Tienen décadas señalando que la apertura económica y la 'estabilidad', reflejada en la baja inflación y los equilibrios macroeconómicos, son condiciones para el crecimiento económico, pero ello no se da. Después pasaron a reconocer que las políticas macroeconómicas de estabilidad eran necesarias, más no suficientes y se requería de las reformas estructurales. Tenemos varios años con estas reformas pero la economía sigue sin crecer y con presiones sobre el sector externo, como los altos niveles de endeudamiento, así como el subempleo, la economía informal y el deterioro del poder adquisitivo de las grandes mayorías del país.

La incertidumbre no se combate con políticas contraccionistas, pues éstas no ofrecen expectativas de crecimiento para promover la inversión, ni resuelven las presiones sobre el sector externo y las finanzas públicas.

Tratan de contrarrestar las presiones que, sobre el sector externo, origina la caída de exportaciones, con políticas restrictivas que contraen la demanda y en consecuencia las importaciones, al optar por un ajuste restrictivo -que profundiza los problemas productivos y financieros de la economía-, hace que sigan las presiones de oferta sobre el sector externo, ya que se requiere importar lo que internamente se deja de producir. $Y$ al disminuir el ingreso nacional se reduce la recaudación tributaria e impide el ahorro fiscal que se pretende. Además, tal política tiende a acentuar los 
problemas de insolvencia que desestabilizarán al sector bancario, el cual demandará rescate fiscal como aconteció en la crisis de 1995.

La incertidumbre permanecerá -mientras siga la misma política económica-, que atenta sobre las condiciones endógenas de acumulación, lo que nos lleva a depender del acontecer internacional y a comprometer la capacidad de reembolso de las obligaciones financieras.

El gobierno mexicano sigue pensando que la economía será ajustada por los mecanismos de mercado, por lo que prosigue con la política de menos Estado y más mercado, a pesar que ello ha fragilizado más a la economía y ha incrementado su vulnerabilidad externa, mismo que nos condena más al subdesarrollo y a seguir perdiendo nuestra soberanía.

En el caso de los países latinoamericanos, la gran mayoría también sigue apostando por la apertura comercial, por lo que seguirán manteniendo tasas de crecimiento bajas o nulas y pierde el potencial de crecimiento, y deteriora más las condiciones de vida de su población. No consideran dejar de lado los tratados de libre comercio, ni flexibilizar la política monetaria y fiscal para recuperar su crecimiento, dado a los altos niveles de endeudamiento, como por la gran fuerza que el sector financiero y las empresas transnacionales, tienen en tales países, que no quieren cambio alguno de la política predominante. En la reunión celebrada en Perú del 14 al 20 de noviembre de 2016, de la Cooperación Económica Asia-Pacífico (APEC, en sus siglas en inglés), los países latinoamericanos participantes, establecieron que seguirán sin Estados Unidos. Es decir, no hay intensión de estos países de revisar la apertura comercial presente en dichas agrupaciones económicas.

No se puede seguir insistiendo en más tratados de libre comercio, en un contexto donde la principal economía del mundo y nuestro principal socio comercial, han optado por políticas proteccionistas. Hay que tomar en cuenta que las políticas económicas son mundiales, proteger a la mayor economía del mundo llevará al resto a instrumentar políticas económicas similares, dado que la estrategia de crecimiento hacia fuera, deja de ser opción, debido a que el resto de las economías muestran bajo crecimiento y no se tiene competitividad frente a la segunda economía del mundo.

\section{México se favorecería saliéndose del TLCAN}

México saldría ganando al dejar el TLCAN, pues podría establecer aranceles a las importaciones provenientes de Estados Unidos y recuperar el manejo de la política industrial, de subsidios y créditos preferenciales en favor de los productores nacionales y avanzar así en la sustitución de importaciones. Puede a su vez, determinar el manejo de las compras gubernamentales en favor de los productores nacionales y a los ubicados internamente.

Dejaría de lado el fuerte proteccionismo a las patentes y a los derechos de autor, que establece el TLCAN, que es contrario al libre comercio, lo que ha llevado a que se establezcan altos precios y se obtengan altas ganancias a los que ostentan dichas patentes, como señala Dean Baker (2017) y otras tantas medidas ahí establecidas que nos han limitado en nuestro desarrollo, lo que permitiría al país, no sólo ahorrar recur- 
sos, sino también para impulsar el desarrollo tecnológico internamente y socializarlo e impulsar la producción y el empleo. Al salirse México del TLCAN deja de estar sujeto a arbitrajes y disputas y soluciones que establezcan los tribunales internacionales.

\section{Desaceleración del comercio mundial y proteccionismo de Estados Unidos}

Se requiere dejar la política económica que ha actuado contra la esfera productiva, el crecimiento económico, la generación de em-

pleo, misma que ha incrementado las presiones sobre el sector externo y los niveles de endeudamiento, que colocado a México en una situación de alta fragilidad y vulnerabilidad ante las políticas proteccionistas que pretende instrumentar el gobierno estadounidense.

Detrás del déficit de cuenta corriente de balanza de pagos, está la apertura comercial indiscriminada y la apreciación cambiaria, con que se trabajó por muchos años, así como la desaceleración del comercio mundial, ahora pasará a acentuarse ante las políticas proteccionistas que instrumente Estados Unidos. A ello se suma la creciente carga del pago de la deuda externa, como a la remisión de utilidades hacia el extranjero y pago de royalties (véase Tabla 5). No hay perspectivas de que ello se reduzca, menos ante el alza de la tasa en Estados Unidos y el creciente proceso de extranjerización de la economía nacional, por lo que las presiones sobre dicho déficit no son temporales, sino que seguirán creciendo.

\begin{tabular}{|l|c|}
\hline Tabla 5 (Datos de 2015 en mmd) & \\
\hline Déficit de Cuenta Corriente de Balanza de Pagos & 33261 \\
\hline Déficit de Comercio Exterior & 14609 \\
\hline Pago de Intereses a la Deuda Externa & 25814 \\
\hline Pago de Utilidades a la Inversión Extranjera & 15874 \\
\hline
\end{tabular}

No se puede seguir con el contexto de una apertura comercial y apostar al crecimiento hacia fuera, pues al no tener los niveles de productividad y competitividad para salir exitos y menos cuando tu principal socio comercial se está protegiendo e impedir que se utilice al tipo de cambio como herramienta competitiva; y además, el comercio internacional se está desacelerando. Tenemos que instrumentar políticas que fortalezcan la economía nacional para generar empleos bien remunerados y que reduzcan la vulnerabilidad externa de México .

De ahí la importancia de dejar de lado la disciplina fiscal y la estabilidad cambiaria, que han atentado sobre las condiciones endógenas de acumulación. Hay que retomar el manejo soberano de la política monetaria, fiscal, crediticia y comercial para asegurar condiciones de rentabilidad en la esfera productiva a fin de generar condiciones de certidumbre para promover la inversión en dicho sector, para sentar las bases para el crecimiento sostenido con la creación de empleos bien remunerados y la reducción de las presiones sobre el sector externo. 
México importa bienes por cerca de 400 mil millones de dólares, lo que representa un gran potencial para crecer y generar empleo a través de la sustitución de importaciones, lo que permitiría reducir el déficit de comercio exterior y los requerimientos de entrada de capital para su financiamiento.

\section{Necesidad de cambio de estrategia de crecimiento}

Muchos hablan de crecer para el mercado interno, pero no se pronuncian por las políticas necesarias para ello. Se requiere la expansión del gasto público, el aumento real de los salarios y la distribución del ingreso; así como regular el movimiento de capitales para evitar prácticas especulativas. También se requiere de una política arancelaria para evitar filtraciones de demanda, generar condiciones de rentabilidad, estimular la inversión e incrementar la producción, a fin de evitar que ésta presión sobre los precios y las importaciones. La flexibilización de la política fiscal requiere de política monetaria y crediticia acomodaticia que acompañe el crecimiento. Ello no es fácil de realizar debido a que hay sectores que se han beneficiado de la política económica imperante. Para recuperar el manejo soberano de la política económica para encaminarla a tales objetivos; implica decisiones políticas, que pasan por una correlación de fuerzas que lo posibilite. Mientras más se demore la toma de conciencia en torno a ello, más difícil y más tiempo llevará salir de los problemas que enfrentamos.

Después de haberse priorizado por años la disciplina fiscal y las políticas de libre comercio a nivel mundial, al parecer se da un vuelco de políticas ante los problemas de bajo crecimiento, desempleo y malestar de amplios sectores de la población

Cabe resaltar que después de haberse priorizado por años la disciplina fiscal y las políticas de libre comercio a nivel mundial, al parecer se da un vuelco de políticas ante los problemas de bajo crecimiento, desempleo y malestar de amplios sectores de la población. Ahora hasta la OCDE -amplia defensora de la austeridad fiscal-, en su Informe sobre Perspectiva Económica Mundial, presentado el 28 de noviembre de 2016, se pronuncia por políticas de expansión del gasto público, para salir del impass en que se encuentra la economía mundial.

Tal cambio de estrategia, será un proceso donde algunos verán reducida su producción en el corto plazo, pues a través de las exportaciones ampliaban su mercado, pero podrán recuperar el mercado interno que habían perdido frente a las importaciones y el crecimiento de éste estimularía mayor inversión nacional e internacional.

Para mejorar los salarios y empleos de calidad, si bien pasa por mejorar los niveles educativos y de destreza y habilidades del capital humano, así como el desarrollo tecnológico, a fin de incrementar la productividad en el sector productivo, en el comercio y servicios, se requiere sobre todo de la fuerza política y de negociación de los trabajadores para asociar el crecimiento de la productividad a los salarios y disminuir los grandes márgenes de ganancia presentes en muchas industrias, así como reducir los diferenciales salariales y de ingreso existentes en entre las economías y al interior de éstas.

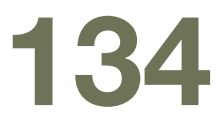




\section{Conclusiones}

Estados Unidos ha reiterado que va a la renegociación del TLCAN para reducir el déficit de comercio exterior

que tiene con México y Canadá. El gobierno de México va a las renegociaciones del TLCAN con el principio fallido de que todos pueden ganar, siendo que los tres han perdido frente a China. No hay espíritu de cooperación por parte de Estados Unidos. Ellos quieren crecer a costa de sus vecinos. Lo intentarán imponiendo restricciones a las importaciones provenientes de tales países, y tratarán de incrementar sus exportaciones a sus socios comerciales. México no tiene poder de negociación frente a Estados Unidos. Al imponerse éste, México verá restringidas sus exportaciones y su crecimiento económico y se incrementará el déficit de comercio exterior, lo que le creará problemas de como ajustarlo, dado que Estados Unidos impondrá la cláusula cambiaria, por lo que al no poder devaluar, el ajuste recaerá con contracción del gasto público y aumento de la tasa de interés, ésta última para estimular entrada de capitales y disminuir la actividad económica y así importaciones. Todo lo cual desemboca en crisis. El libre comercio defendido por el gobierno, dio de si. No ofrece perspectivas de crecimiento, dada la baja productividad y competitividad de México, la desaceleración del comercio mundial y del proteccionismo que establecerá Estados Unidos. Hay que replantear la estrategia de crecimiento, y volcarse hacia el mercado interno y sustituir importaciones, lo que requiere regular el movimiento de mercancías y capitales y que el gobierno recupere el manejo de la política económicos a favor del incremento de demanda, del sector productivo y de la generación de empleo bien remunerado.

\section{Bibliografía}

BAKER, D. (2016) “Trade, Trump, and Profit Shares”, en www.cepr.net , 13 Nov.

BAKER, D. (2017) "End Patent and Copyright Requirements in Nafta”, The New York Times, Ene. 30.

DOLAN, E. (2016) "Trade and Jobs: Why the Protectionist Cure Could be Worse Than the Globalization Disease", en www.economonitor.com, Nov. 28.

FARHI, E., et al (2017), "Trump's Tax Plan and the Dollar", en www.project-syndicate.org Ene. 3.

KRugman, P. (2016), “La guerra comercial que viene”, El País, Dic. 29.

PIGmAN, G. (2016), "Seeing Past US Hegemony: A Liberal Global Trading System Without the United States", en www.economonitor.com Dic. 19.

SPENCE, M. (2016), "How to Fight Secular Stagnation”, en www.project-syndicate.org Ago. 30. 